\title{
QUALIDADE DE VIDA E PERCEPÇÃO AMBIENTAL DOS MORADORES DE COMUNIDADES RURAIS EM SÃO LUÍS (MA)
}

\author{
Lara Rita Albuquerque Camara ${ }^{1}$ \\ Debora Danna Soares da Silva² \\ Layse Lorena Neves Sales ${ }^{3}$ \\ Darlann Weskley Sousa Silva ${ }^{4}$ \\ Eduardo Mendonça Pinheiro 5
}

Resumo: A reflexão sobre percepção ambiental é uma ferramenta para a Educação Ambiental e para as políticas públicas relacionadas ao meio ambiente. Através da percepção ambiental são estabelecidas as relações de afetividade do indivíduo para com o ambiente, possibilitando identificar as formas precisas em que essa educação possa sensibilizar e trabalhar as dificuldades ou dúvidas que os envolvidos possam vir a ter em relação às questões ambientais. Este trabalho objetivou investigar a percepção ambiental dos moradores das comunidades Inhaúma e Igaraú, localizadas na Zona Rural de São Luís (MA), assim como delinear os principais problemas socioambientais das comunidades. Para tal foram aplicados 117 questionários semiestruturados em residências escolhidas aleatoriamente. Foram observados que as más condições de infraestrutura e pouco acesso ao saneamento básico é uma realidade no dia-a-dia dos moradores das comunidades estudadas. E que políticas voltadas à conscientização ambiental pode ser uma solução imediata para melhoria da qualidade ambiental das comunidades.

Palavras-chave: Saneamento Básico; Condições Socioambientais; Educação Ambiental.

\footnotetext{
${ }^{1}$ Faculdade Pitágoras São Luís. E-mail: lararitacamara@gmail.com.

2 Universidade Estadual do Maranhão. E-mail: dannasilva94@gmail.com.

3 Faculdade Pitágoras São Luís. E-mail: lorenasales.eng@gmail.com.

${ }^{4}$ Faculdade Pitágoras São Luís. E-mail: darlannsousa@hotmail.com.

${ }^{5}$ Faculdade Pitágoras São Luís. E-mail: eduardomp1979@gmail.com.
} 


\section{Introdução}

A percepção ambiental pode ser definida como sendo uma tomada de consciência do ambiente pelo homem, ou seja, o ato de perceber o ambiente que se está inserido, aprendendo a proteger e a cuidar do mesmo (MALAFAIA; RODRIGUES, 2009). O conhecimento da percepção ambiental de determinados grupos possibilita a elaboração de ações de conscientização voltadas a cada realidade (FAGGIONATO, 2009).

Cada indivíduo percebe o ambiente, reage e responde a este de forma diferenciada e individual. As respostas ou manifestações daí decorrentes são resultado das percepções (individuais e coletivas), dos processos cognitivos, julgamentos e expectativas de cada indivíduo (VILLAR et al., 2008). Desta forma, o estudo da percepção ambiental é de suma importância para a melhor compreensão das relações que os seres humanos estabelecem com os locais nos quais habitam, ou seja, suas expectativas, satisfações e insatisfações, julgamentos e condutas (ZAMPIERON et al., 2003; FAGGIONATO, 2009; SANTOS et al., 2017).

Sabe-se que as questões ambientais têm se tornado cada vez mais urgentes, principalmente nas últimas décadas, seja pelas mudanças provocadas pela ação do homem na natureza ou pela resposta que a natureza dá a estas ações (HAUBRICHT; FIORINI, 2014). Existe uma crescente preocupação de estudos relacionados às análises ambientais, particularmente no que se refere às intervenções da sociedade na natureza (BRUNA, 2004 apud SANTOS et al., 2017).

Um dos grandes problemas ambientais em discussão ultimamente é a ineficiência do serviço de saneamento básico, devido surgimento de diversas anomalias oriundas da ausência desses serviços (FONTES, 2017). A Organização Mundial da Saúde (OMS) (2015) evidência que há no mundo cerca 2 bilhões de pessoas que não detém de condições adequadas de saneamento básico, ocasionando diversas doenças de veiculação hídrica.

Segundo dados da Agência Nacional de águas (ANA) (2017), em São Luís, apenas $48,09 \%$ da população é atendida com a rede de esgoto, no que diz respeito ao tratamento desses resíduos os dados são mais alarmantes ainda, uma vez que só 3,78\% do esgoto coleto é tratado, conforme (Figura 1). 


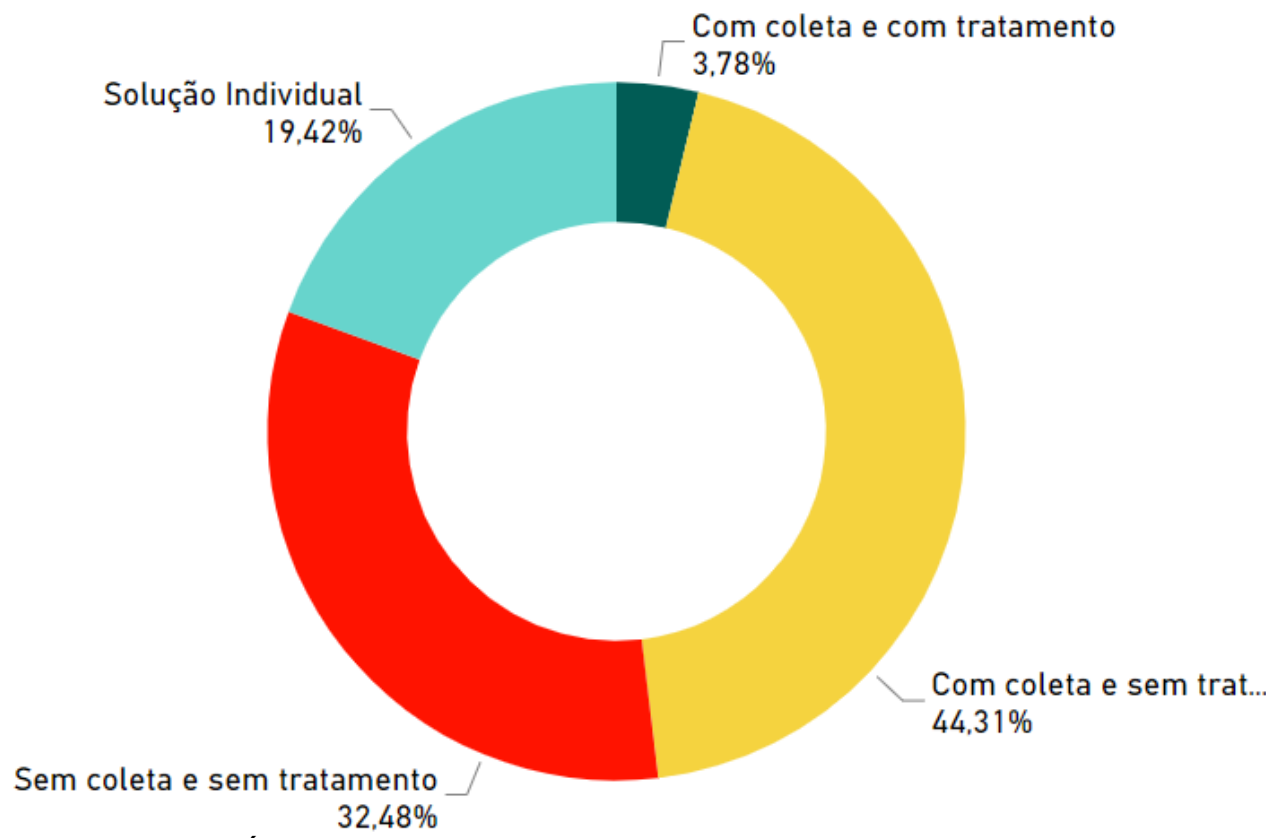

Figura 1: Índice de atendimento do esgotamento sanitário em São Luís.

Fonte: ANA (2017)

É notório que é impossível realizar uma efetiva proteção à saúde populacional sem praticar cuidados básicos ao meio ambiente, assim, não se pode pensar em danos ao meio, sem associar danos à saúde individual e coletiva (PHILIPPI; ARLINDO, 2005).

Diante disso, a necessidade de levantamentos da percepção ambiental é importante para identificar qual representação social que cada parcela da sociedade tem do meio ambiente (HAUBRICHT; FIORINI, 2014). Portanto, este trabalho tem como objetivo diagnosticar o cenário ambiental junto com os moradores da comunidade rural Inhaúma e Igaraú, localizada na zona rural de São Luís/MA, circunvizinhas de um Polo Industrial.

\section{Metodologia}

\section{Área de estudo}

O estudo foi realizado com as comunidades rurais Inhaúma e Igaraú, localizada na zona rural de São Luís/MA, circunvizinhas de um Polo Industrial. A comunidade Inhaúma localizada nas coordenadas geográficas $2^{\circ} 32^{\prime} 58.95^{\prime \prime}$ $S$ e $44^{\circ} 19^{\prime} 28.28^{\prime \prime} \mathrm{O}$ e a comunidade Igaraú está sob as coordenadas $2^{\circ} 45^{\prime}$ $36.81^{\prime \prime} \mathrm{S}$ e $44^{\circ} 19^{\prime} 26.70^{\prime \prime} \mathrm{O}$, conforme (Figura 2). 



Figura 2: Mapa de localização das comunidades pesquisadas.

Fonte: Autores (2018)

A comunidade Inhaúma encontra-se localizada nos limites do Parque Estadual (PE) do Bacanga e próxima a Área de Proteção Ambiental (APA) do Maracanã, já a comunidade Igaraú situa-se nas redondezas na APA UpaonAçu/Miritiba/Alto Preguiças. As duas comunidades estão situadas próximas de corpos hídricos que legalmente pertencem à marinha e a união.

A comunidade Inhaúma influência o Rio Bacanga e a Baia de São Marcos, e a comunidade Igaraú interliga a Baia Arraial com Baia de São Marcos com influência dos rios Mearim e Perízes. A bacia hidrográfica da comunidade Inhaúma possui $27,51 \mathrm{~km}^{2}$ e recebe vários rios, incluindo Grajaú, Mearim e Pindaré.

\section{Coleta de dados}

Trata-se de um estudo quantitivo-descritivo, onde foram utilizados 117 questionários especialmente delineados e pré-testados, contendo 26 perguntas que inicialmente caracterizavam o perfil social dos entrevistados em relação ao gênero e idade. Também caracterizavam as condições sanitárias das comunidades, assim como a percepção dos moradores acerca do meio ambiente, qualidade e responsabilidade ambiental. 
Os questionários foram aplicados em 84 residências da comunidade Inhaúma e 33 residências da comunidade Igaraú, zona rural do município de São Luís, MA, escolhidas randomicamente. As entrevistas domiciliares foram feitas em um período de 06 dias (28/11/2016 a 05/12/2016). Os dados foram tabulados no Programa Excel do Windows para a posterior análise.

\section{Resultados e Discussão}

No diagnóstico do perfil social dos entrevistados os resultados demonstraram que $62 \%$ dos questionados eram do sexo feminino e $38 \%$ do sexo masculino, número total das duas áreas estudadas. A faixa etária variou entre 18 e 25 anos e 51 e 65 anos na comunidade Inhaúma e 51 e 65 anos na comunidade Igaraú. Essas famílias, em geral, possuíam seu núcleo residencial média de 3,6 indivíduos.

$\mathrm{Na}$ investigação das condições ambientais de habitação, notou-se a simplicidade das moradias encontradas, geralmente com apenas dois cômodos. Do ponto de vista do paradigma do ambiente como aspecto decisivo na saúde, a habitação apresentou-se como espaço essencial, para a construção e o desenvolvimento da Saúde da Família (COHEN et al., 2004). Observou-se ainda, a precariedade habitacional, ambientes insalubres, com deterioração da qualidade de vida e impacto na saúde, havendo a necessidade de um aumento na eficiência e eficácia das políticas públicas.

No que tange a situação do meio, foi observado nas duas comunidades estudadas que ao decorrer dos anos houve uma significativa supressão da vegetação nativa, transformando parte da área em grandes campos erodidos ou com ocupação desordenada sem qualquer previsão de planejamento urbano ambiental. Consequentemente, esta supressão pode ter interferido no curso natural de alguns leitos, no afloramento de olhos d'aguas existentes e no assoreamento de corpos hídricos.

Silva (2010) aponta que, dentre os efeitos mais perversos da perda de vegetação deve-se destacar a produção excessiva de sedimentos, a impermeabilização do solo, a perda e alteração de habitat e da biodiversidade, o aumento do escoamento superficial de água, a elevação da temperatura, entre outros.

Nas áreas estudadas, além da ocorrência de desmatamento para retirada de matéria prima, agricultura, pecuária e escavação de poços irregulares foi notável os desvios de curso d'água para extração de minerais, onde os responsáveis não possuem autorizações para efetuar tal atividade.

Segundo Philippi Jr. et al. (2002) localidade onde não obedece a legislação de uso e ocupação do solo, nem legislação ambiental, certamente está propicia a problemas como poluição do ar e água, que por sua vez, pode distribuir doenças pela comunidade afora, afetando leitos, população e a economia. 
Vale ressaltar que as comunidades estudadas se localizam nas proximidades dos limites da APA Upaon-Açu/Miritiba/Alto Preguiças e do Parque Estadual do Bacanga, Unidades de Conservação de proteção sustentável. Logo é de suma importância a proteção destas áreas, uma vez que possuem funções ecológicas como a proteção da fauna e flora, além de servirem como área de drenagem e ponto de recarga de aquíferos, dentre outros benefícios ambientais.

Junto aos impactos gerados pela própria população, destacaram-se os impactos oriundos das indústrias próximas, ambas por material particulado em seu estado sólido (poeira) ou líquido (vapor) que ficam suspensos no ar, sendo carreados pela influência da chuva ou do próprio vento, contaminando o solo e corpos hídricos.

Quanto ao conhecimento dos entrevistados sobre o meio ambiente, a comunidade Igaraú possuía maior grau de conhecimento sobre o tema. A maioria dos entrevistados desta comunidade (56\%) responderam que o meio ambiente se trata de algo que deve ser preservado e apenas $18 \%$ não souberam responder (Figura 3).

Haubricht e Fiorini (2014) afirmaram que tudo que o homem faz à natureza acaba determinando a sua qualidade de vida, e que, a falta de conhecimento sobre o elemento da natureza e suas leis, pode levar a grandes desequilíbrios ambientais. Desta forma, o homem é um dos principais elementos da natureza e interage permanentemente com ela.

Quando indagados sobre a importância dos rios e igarapés, notou-se que comunidade Igaraú possui maior conhecimento sobre o referido assunto, $56 \%$ dos moradores entrevistados nessa comunidade, pontuaram que os recursos hídricos são importantes, pois são meios de sobrevivência, como pode ser observado na (Figura 3 ), isso pode estar relacionado ao maior número de pescadores moradores da área que utilizam os corpos hídricos para geração de renda.

\section{IMPORTÂNCIA DOS RIOS E IGARAPÉS}

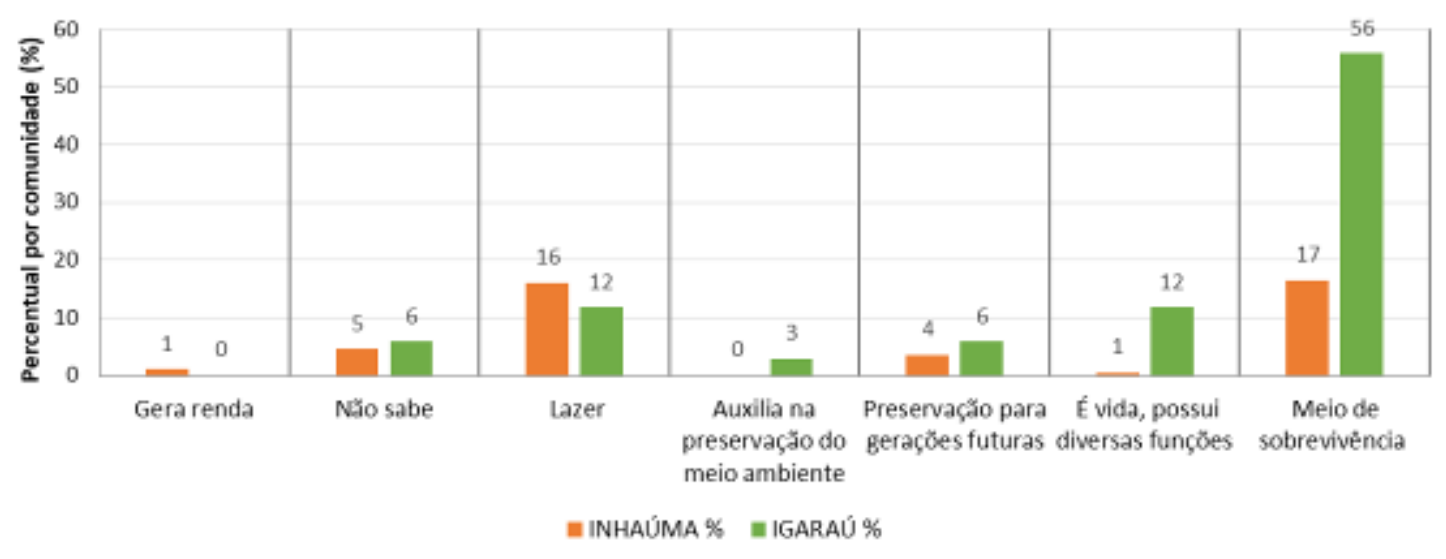

Figura 3: Importância dos rios e igarapés segundo os moradores das comunidades estudadas. Fonte: Autores (2018) 
Em relação às condições de saneamento das comunidades, de acordo com os entrevistados ambas as comunidades não possuíam rede coletora de esgoto, por isso supõe-se que estes moradores devam destinar seus efluentes domésticos para fossas sépticas, vias públicas e/ou até fossas negras. A água de $94 \%$ dos moradores de Igaraú é proveniente de poço, já na comunidade Inhaúma $99 \%$ da água consumida pelos moradores é abastecida pela Companhia de Saneamento Ambiental do Maranhão (CAEMA). A maioria da população entrevistada da comunidade Inhaúma (67\%) afirmaram que o lixo era submetido ao procedimento de coleta pela Prefeitura Municipal, 31\% costumam queimar e $2 \%$ dispõe em local irregular ou queimam, enquanto na comunidade Igaraú, $85 \%$ dos moradores declararam que destinam o lixo para coleta, 9\% afirmaram queimar estes materiais e 6\% disseram destinar para locais inapropriados ou enterrar. Os dados apresentados podem ser visualizados nas (Figuras 4 e Figura 5).

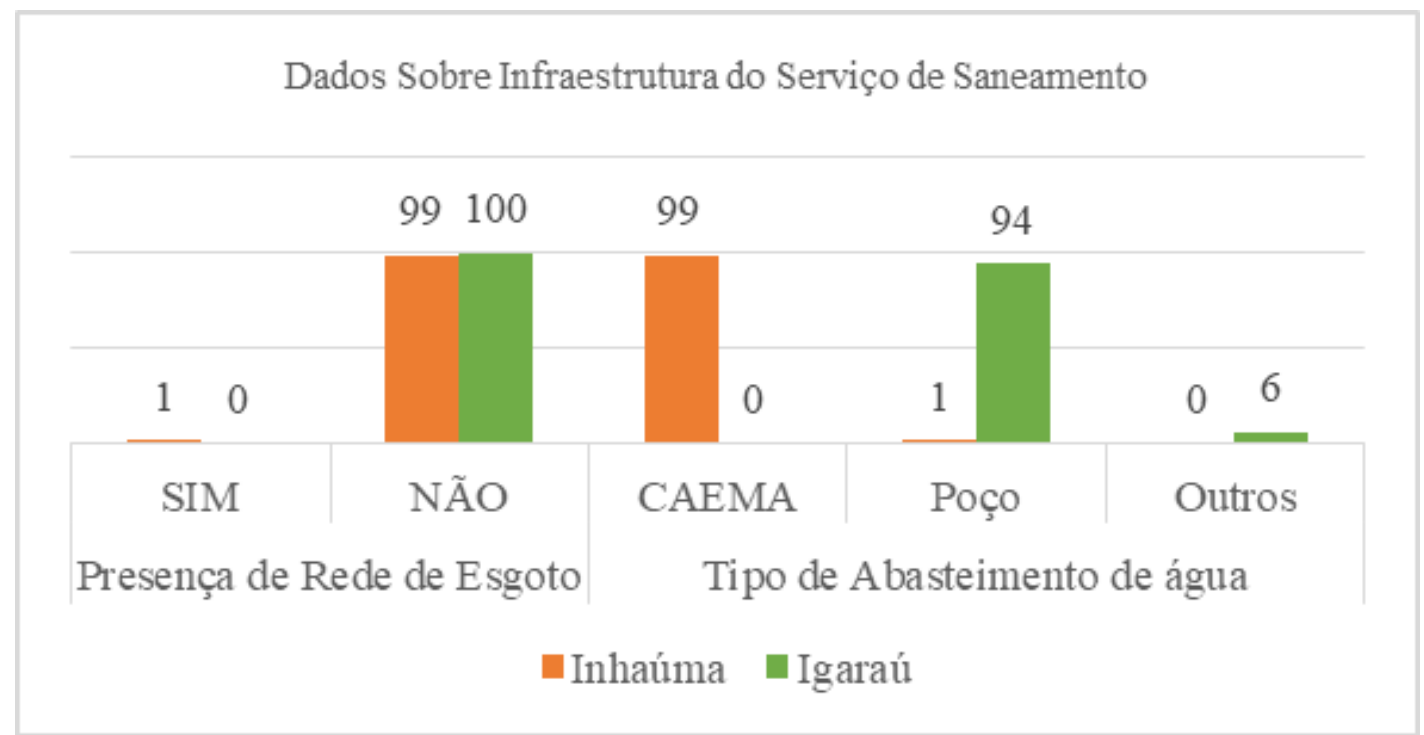

Figura 4: Presença de saneamento básico nas comunidades.

Fonte: Autores (2018)

Resultados semelhantes foram obtidos por outros autores que tiveram como objeto de estudo o saneamento básico na comunidade rural, como Bezerra et al. (2010), Costa e Oliveira Filho (2012), Carvalho et al. (2013) e Haubricht e Fiorini (2014).

No que diz respeito ao esgotamento sanitário, ao se destinar efluentes líquidos para fossas negras e vias públicas, propicia-se a infiltração do esgoto no solo, com risco constante de contaminação da área e do lençol freático, além da transmissão de inúmeras doenças, como a hepatite, cólera e salmonelose (RIBEIRO; ROOKE, 2010).

As más condições de esgotamento sanitário e saneamento estão como uma das principais causas para a ocorrência de doenças infecciosas, de acordo com a Organização Mundial de Saúde, considera que a falta de 
saneamento básico é uma das 10 principais causas de graves consequências para o ser humano (TRATA BRASIL, 2014).

Souza et al. (2015) em estudo sobre as condições de saneamento de uma comunidade rural do município de Barreiras/BA, constataram, também, que os principais problemas vivenciados pela comunidade eram, 0 não tratamento da água captada do poço, o lançamento de efluentes no solo e a baixa abrangência da coleta de lixo, se igualando com a realidade de diversas comunidades da zona rural do Brasil.

De acordo com os dados do IBGE (2010), em São Luís, 33\% das casas estão em lugares, onde o esgoto escoa por cima das ruas, os considerados esgotos a céu aberto, e são residências que apresentam condições mínimas de moradia.

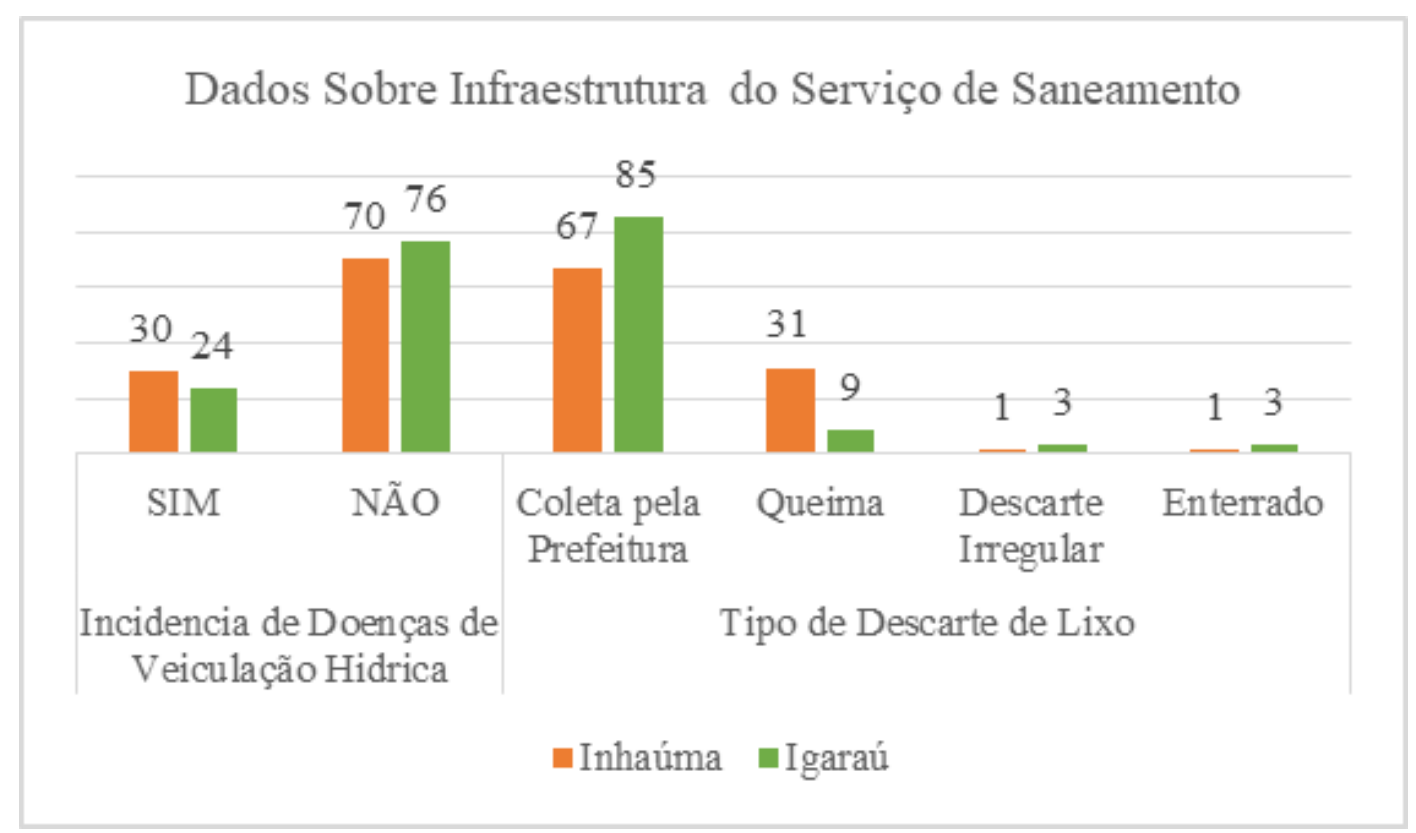

Figura 5: Presença de doenças por veiculação hídrica e tipo de descarte de lixo.

Fonte: Autores (2018) 
contribuindo para a poluição atmosférica, além de prejudicar a saúde do homem (DEBONI et al., 2010).

Em relação das doenças transmitidas por veiculação hídrica, devido à deficiência nos serviços de saneamento, mesmo que durante a aplicação do questionário poucas pessoas tenham relatado ocorrências dessas, como pode ser visto na Figura 4, é importante está atendo para esse aspecto, uma vez que a infraestrutura das cidades, o nível educacional da população, temperatura, alimento e qualidade da água são fatores que favorecem a proliferação vetores, como o Aedes aegypti (UNISINOS, 2016).

Quando indagados sobre das práticas ambientais adotadas no seu dia a dia, a fim de melhorar o ambiente em que vivem, observa-se na Figura 6 que foram identificadas que a maioria dos entrevistados não desenvolvem nenhuma ação ambiental.

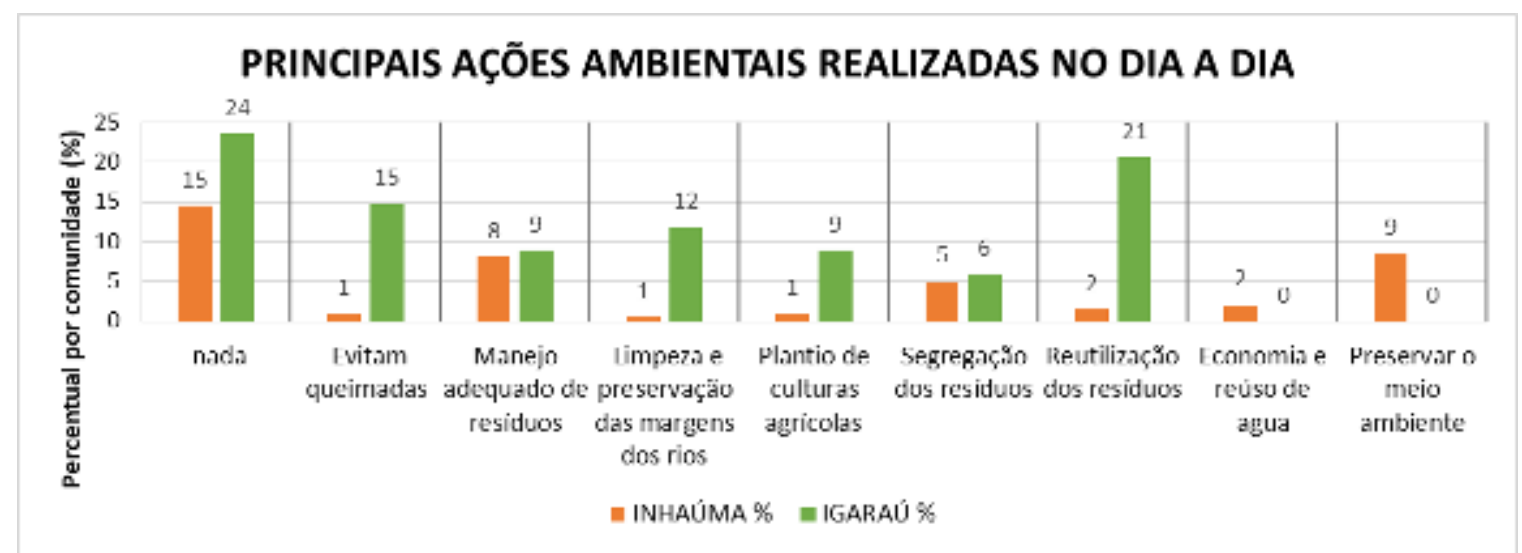

Figura 6: Principais ações ambientais realizadas pelos moradores de cada comunidade.

Fonte: Autores (2018)

Ambas as comunidades desenvolvem poucas ações ambientais no seu dia-a-dia, devido a pouca conscientização ambiental dos seus moradores.

Nascimento et al. (2016) recomendam a prática da Educação Ambiental para fortalecer as primícias do saneamento e assim identificar pontos de melhoria pelos moradores. Aplicar políticas que demonstrem a importância da Educação Ambiental, na comunidade, possibilita a criação de nova mentalidade com relação aos problemas enfrentados.

Considerando as informações levantadas por meio do questionário socioeconômico e ambiental, pode-se constatar que a comunidade Igaraú é a mais carente de recursos públicos.

Notou-se existir um grande anseio por parte dos moradores por mais qualificação e informações que possibilitem o incremento da renda local, bem como, possa contribuir para melhoria da qualidade ambiental das comunidades e direcionar os jovens a construção de uma cultura conservacionista garantindo a sustentabilidade dos recursos naturais ainda existentes em suas comunidades. 
Tal sensibilização e reconhecimento como protagonistas ativos ou passivos dos problemas ambientais da comunidade estão proporcionalmente relacionados aos princípios básicos da Educação Ambiental. Vale informar que, Smith et al. (1995) ressalta que os princípios gerais da Educação Ambiental envolvem a sensibilização, compreensão, responsabilidade, competência e cidadania.

\section{Conclusões}

A qualidade de vida dos moradores da comunidade Inhaúma e Igaraú está comprometida devido às precárias condições de infraestrutura e de saneamento existentes.

Constatou a falta do tratamento adequado da água na comunidade Igaraú também expõe a comunidade a doenças de veiculação hídrica.

Em ambas as comunidades não há ações efetivas por parte da população. Boa parte dos entrevistados possuem interesses em informações quando se trata de assuntos voltados ao meio ambiente, reafirmando a necessidade de ações de Educação Ambiental nas comunidades.

\section{Referências}

ANA. Agência Nacional de Águas (Brasil). Atlas esgotos: despoluição de bacias hidrográficas / Agência Nacional de Águas, Secretaria Nacional de Saneamento Ambiental. Brasília: ANA, 2017.

BAY, A.M.C.; SILVA, V.P. Percepção ambiental de moradores do bairro de liberdade de Parnamirim/RN sobre esgotamento sanitário. Revista HOLOS, Rio Grande do Norte, Natal, v. 3, n. 27, p.101-101, 2011.

BEZERRA, J.A.B.; FRANÇA, L.S.; OLIVEIRA, C.R.M.; BEZERRA, F.S.B. Aspectos do saneamento básico em uma comunidade rural de Mossoró, RN. In: Encontro de Pesquisa e Extensão, 16., 2010. Mossoró/RN. Anais... . Mossoró: UERN, 2010.

BRASIL. Lei $n^{\circ}$ 12.305, de agosto de 2010. Política Nacional de Resíduos Sólidos.

CARVALHO, A.R.; BUGANA, G.O.; NUNES, I.V.O.; BERNARDES, M.E.C. O saneamento rural: um estudo de caso na comunidade barreirinho, em Delfim Moreira (MG). In: Congresso Brasileiro de Gestão Ambiental, 4., 2013. Salvador/BA. Anais... Salvador, 2013. 
COHEN, S.C.; SYNAMON, S.E.; KLIGERMAN, D.C.; ASSUMPÇÃO, R.F. Habitação saudável no Programa Saúde da Família (PSF): uma estratégia para as políticas públicas de saúde e ambiente. Ciência \& Saúde Coletiva, v. 9, n. 3, p. 807-813, 2004.

COSTA, M.I.F.; PIRES, M.G. Levantamento dos impactos ambientais em áreas de preservação permanentes (APPS) urbanas em Porangatu - GO. Revista Meio Ambiente e Sustentabilidade, v. 13, n. 6 Curitiba- PR. Jun/Dez - 2017.

COSTA, F.A.M.; OLIVEIRA FILHO, R.L.C. Avaliação das condições de saneamento ambiental na comunidade de Camurim - Iraiçaba/CE. 2012. Disponível em: <http://www.ihab.org.br/o2015/trabalhos completos/6.pdf>. Acessado em: 31/01/2018.

DEBONI, L.; PINHEIRO, D.K. Estudo sobre a destinação do lixo na zona rural de Cruz Alta/RS- Passo dos alemães. Revista Eletrônica em Gestão, Educação e Tecnologia Ambiental. REGET-CT/UFSM, v. 1, n. 1, p. 20. 2010.

FAGGIONATO, S. 2009. Percepção ambiental. Disponível em: $<$ http://educar.sc.usp.br>. Acesso em: 22/01/2018.

FONTES, A.R. Análise socioambiental da microbacia do rio Caiçá no perímetro urbano de Simão Dias/SE. 2016. 175 f. Tese (Dissertação) - Mestrado em Desenvolvimento e Meio Ambiente - Universidade Federal de Sergipe, 2016.

HAUBRICHT, D.M.; FIORINI, F.A. Percepção ambiental dos moradores do assentamento vila rural e do município de Alta Floresta/MT. Revista da Universidade Vale do Rio Verde, Três Corações, v. 12, n. 1, p.248-256, 2014.

JUNIOR, E.F.O.; FREIRE, R.S. Os impactos ambientais decorrentes da produção de resíduos sólidos urbanos e seus riscos a saúde humana. Revista Eletrônica da Faculdade José Augusto Vieira, Lagarto/SE, v. 6, n. 8, p.12851983, set. 2013.

MALAFAIA, G.; RODRIGUES, A.S.L. Percepção ambiental de jovens e adultos de uma escola municipal de ensino fundamental. Revista Brasileira de Biociências, v. 7, n. 3, 2009.

NASCIMENTO, M.S.; RABELO, A.C.P.; PEREIRA, D.R., ROCHA, D.B.J.R., REIS, N.S.S. Caracterização do Saneamento Básico com aplicação de Educação Ambiental em uma Comunidade em São Luís/MA. In: Simpósio Internacional de Qualidade Ambiental, 10, 2016. Porto Alegre. Anais... Porto Alegre, PUCRS, 2016. 
ORGANIZAÇÃO MUNDIAL DE SAÚDE. Progress and sanitation and drinking water: Update 2015. Disponível em: $<$ http://apps.who.int/iris/bitstream/10665/177752/1/9789241509145 eng.pdf?ua $=1>$. Acesso em: 02/02/2018.

PHILIPPI Jr., ARLINDO. B. Saneamento, Saúde e Ambiente - Fundamentos para um Desenvolvimento Sustentável. 2. ed. Barueri-SP: Manole, 2005. 842 p.

PHILIPPI JR; ARLINDO, B; ALVES, A.; ROMÉRO, M.A.; BRUNA, G.C. (ed.). Meio ambiente, direito e cidadania. São Paulo: SIGNUS Editora, 2002.

RIBEIRO, J.W.; ROOKE, J.M.S. Saneamento básico e sua relação com o meio ambiente e a saúde pública. 2010. 36 f. TCC (Especialização) - Curso de Especialização em Análise Ambiental, Universidade Federal de Juiz de Fora, Juiz de Fora, 2010.

SANTOS, K.P.P.; VIEIRA, I.R.; ALENCAR N.L.; SOARES, R.R.; BARROS, R.F.M. Percepção ambiental sobre a degradação dos recursos hídricos na comunidade de pescadores artesanais de Miguel Alves/Brasil. Educação Ambiental em Ação, v. 59, n. 15, Março-Maio/2017.

SILVA, L.S. Impactos da Perda de Vegetação nas Áreas Periurbanas Metropolitanas no Contexto da Dispersão Urbana. In: Encontro Nacional da ANPPAS, 5., 2010, Florianópolis-SC. Anais... . Florianópolis: ANPPAS, 2010.

SOUZA, K.S.; DUTRA, L.K.A.; RÊGO, N.F.L.; SILVA, J.F. Levantamento das condições de saneamento na comunidade $\mathrm{km} 32$, zona rural de Barreiras-BA. In: Simpósio Brasileiro de Recursos Hídricos, 21., 2015, Brasília-DF. Anais... . Brasília-DF, 2015.

VILLAR, L.M; ALMEIDA, A.J; LIMA, M.C.A.; ALMEIDA, J.L.V.; SOUZA, L.F.B.; PAULA, V.S. A percepção ambiental entre os habitantes da região noroeste do Estado do Rio de Janeiro. Escola Anna Nery Revista de Enfermagem, Rio de Janeiro, v. 2, n. 12, p.285-290, jun. 2008.

WHO. The World Health Report 1998: Life in the 21st Century - A Vision for All. WHO, Genebra. 1998. 241p.

ZAMPIERON, S.L.M.; FAGIONATO, S.; RUFFINO, P.H.P. Ambiente, representação social e percepção. In: SCHIEL, D. et al. (Org.). $O$ estudo de bacias hidrográficas: uma estratégia para Educação Ambiental. 2. ed. São Carlos: RIMA, 2003. p. 17-20. 